\title{
Nitric oxide-active compounds modulate the intensity of glutamate-evoked responses in the globus pallidus of the rat
}

\author{
Pierangelo Sardo *, Fabio Carletti, Valerio Rizzo, Gioacchino Lonobile, Simonetta Friscia, Giuseppe Ferraro

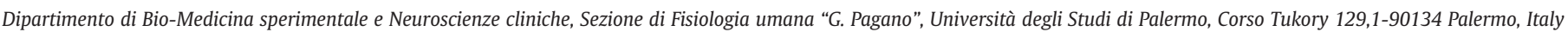

\section{A R T I C L E I N F O}

\section{Article history:}

Received 4 August 2010

Accepted 4 April 2011

\section{Keywords:}

Nitric oxide

Basal ganglia

Single unit electrophysiology

Microiontophoresis

\begin{abstract}
A B S T R A C T
Aim: The effects of local applied NO-active compounds on glutamate (GLU)-evoked responses were investigated in globus pallidus (GP) neurons.

Main methods: Extracellularly recorded single units from anesthetized rats were treated with GLU before and during the microiontophoretic application of S-nitrosoglutathione (SNOG), a NO donor, and NW-nitro-Larginine methyl ester (L-NAME), a NOS inhibitor.

Key findings: Most GP cells were excited by SNOG whereas administration of L-NAME induced decrease of GP neurons activity. Nearly all neurons responding to SNOG and/or L-NAME showed significant modulation of their excitatory responses to the administration of iontophoretic GLU. In these cells, the changes induced by NO-active drugs in the magnitude of GLU-evoked responses were used as indicators of NO modulation. In fact, when a NO-active drug was co-iontophoresed with GLU, significant changes in GLU-induced responses were observed: generally, increased magnitudes of GLU-evoked responses were observed during SNOG ejection, whereas the administration of L-NAME decreased responses to GLU.

Significance: The results suggest that the NO-active drugs modulate the response of GP neurons to glutamatergic transmission. Nitrergic modulation of glutamatergic transmission could play an important role in the control of GP bioelectric activity, considered a fundamental key in the BG function.
\end{abstract}

(c) 2011 Elsevier Inc. All rights reserved.

\section{Introduction}

The globus pallidus (GP) of rodents, homologous to the external GP of primates, plays a critical role in basal ganglia (BG) function, by virtue of rich reciprocal connections with the other nuclei belonging to the BG system. The activity of GP neurons is controlled by three major sources: striatal GABAergic inhibitory inputs, subthalamic glutamatergic excitatory inputs, and BG intrinsic collateral inhibitory inputs (Hazrati and Parent, 1992; Parent et al., 2000; Nambu et al., 2000). Furthermore, GP also receives external excitatory projections, such as cortical inputs from frontal cortex, thalamo-pallidal fibers arising from neurons located in the parafascicular nucleus, serotoninergic innervation from the dorsal raphe nucleus, and cholinergic/GABAergic/glutamatergic projection from the pedunculopontine tegmentum (Parent and Hazrati, 1995; Naito and Kita, 1994; Mouroux et al., 1997; Yasukawa et al., 2004; Chen et al., 2008). In turn, GABAergic GP neurons project to the striatum, the subthalamic nucleus (STN), both the substantia nigra pars compacta (SNpc) and pars reticulata (SNpr) and the entopeduncular nucleus, homologous to the internal segment of the GP in primates (Sato et al., 2000; Lee and Tepper, 2009).

\footnotetext{
* Corresponding author at: Dipartimento di Medicina sperimentale Sezione di Fisiologia umana "G. Pagano" Università degli Studi di Palermo Corso Tukory, 129 I-90134 Palermo, Italy. Tel.: + 3909165558 01; fax: + 390916555816 .

E-mail address: pierangelo.sardo@unipa.it (P. Sardo).
}

Glutamatergic inputs have been demonstrated to greatly modulate the spontaneous (Bevan et al., 2002) GP activity through the activation of both AMPA/kainate and NMDA receptors (Kita et al., 2004), aside with metabotropic glutamate receptors (mGluRs) (Conn et al., 2005; Rouse et al., 2000). The glutamatergic drive to the GP neuronal activity has been shown to be differently modulated by classical neurotransmitters and neuromodulators (Chen et al., 2006; Hernandez et al., 2007).

In this regard, our previous studies have shown marked effects induced on the activity of GP neurons by drugs modulating the nitric oxide (NO) neurotransmitter system (Sardo et al., 2002a, 2003). Such gaseous messenger is a modulator of neurotransmission (Prast and Philippu, 2001) and the neuronal isoform of NO-synthase (nNOS), the NO-producing enzyme, is widely distributed in the rat brain (De Vente et al., 1998), including GP (Rodrigo et al., 1994). In a previous study we observed that the systemic administration of 7-nitro-indazole, a preferential inhibitor of nNOS, induced a decrease of the firing rate of responsive GP neurons; similarly, the microiontophoretic application of N $\omega$-nitro-L-arginine methyl ester (L-NAME), a nonspecific inhibitor of nNOS, induced a decrease in the firing rate of most recorded neurons; furthermore, the local administration of 3-morpholinosydnonimin-hydrocloride (SIN-1), a NO donor, induced an increase of the firing activity of GP neurons (Sardo et al., 2002a). Moreover, in a recent in vivo study we highlighted a NO-induced modulation of GABAergic and glutamatergic neurotransmission in the STN (Sardo et 
al., 2009). In order to explore whether an interaction between glutamatergic and NO systems takes place in the GP, in this study we compared the effects of the iontophoretic administration of glutamate (GLU) before and during the co-administration of either L-NAME or Snitroso-glutathione (SNOG, a NO donor) in extracellullarly recorded GP neurons.

\section{Material and methods}

\section{Animals and surgery}

The study was performed on 36 male Wistar rats (Morini, Italy) weighing 220-280 g on the day of the experiment, anesthetized with urethane (Sigma Chemical Co., St. Louis, MO, U.S.A.) at the dose of $1.2 \mathrm{~g} / \mathrm{kg}$ i.p. Animals were positioned in a stereotaxic apparatus (David Kopf Instruments, Tujunga, CA, U.S.A.). Body temperature was maintained at $37-38{ }^{\circ} \mathrm{C}$ using a heating pad. Heart rate and pupillary diameter were monitored throughout all experimental sessions. A $3 \mathrm{~mm}$ burr hole was drilled in the skull $(7.7 \mathrm{~mm}$ anterior to the interaural line, $3.1 \mathrm{~mm}$ lateral to the midline). In each experimental step, all efforts were made to minimize the number of animals used and their suffering. All experiments were performed in strict accordance with the Italian laws on animal experimentation (D.L. 116/1992) and with the National Institute of Health Guide for the Care and Use of Laboratory Animals (1986).

\section{Electrophysiological recordings}

Seven-barrel glass microelectrodes were directed stereotaxically (Paxinos and Watson, 1998) to the GP (7.2-8.2 $\mathrm{mm}$ anterior to the interaural line, $2.6-3.6 \mathrm{~mm}$ lateral to the midline, $5-7 \mathrm{~mm}$ ventral to the cortical surface). The center recording barrel (1.1-2.0 M $\Omega$ ) was filled with $2 \mathrm{M} \mathrm{NaCl}$ with $1 \%$ Fast Green (Sigma). The side barrels were filled with a $2 \mathrm{M} \mathrm{NaCl}$ solution (for automatic current balancing), SNOG (15 mM, pH 4.5), L-NAME (50 mM, pH 6.5) L-glutamic acid monosodium salt (GLU; $100 \mathrm{mM}, \mathrm{pH} 8$ ), respectively. Retaining currents of 8-10 nA were applied to drug barrels (20-70 M $\Omega$, positive for GLU, negative for the other solutions) (Neurophore BH-2 System, Harvard Apparatus, Holliston, MS, U.S.A.). At the beginning of each track ( $0.5 \mathrm{~mm}$ ventral to the cortical surface), maximal ejection currents were applied to each of the drug-containing barrel for $30 \mathrm{~min}$, to concentrate the drug at the pipette tip.

Electrical signals were amplified and filtered $(300 \mathrm{~Hz}-1.5 \mathrm{kHz}$ band pass) through a Grass (West Warwick, RI, U.S.A.) AC amplifier (mod. P511) and audio monitored. The raw activity signal was video monitored through a Tektronix (Beaverton, OR, U.S.A.) oscilloscope (mod. 5113). It was then isolated through a World Precision Instruments (Sarasota, FL, U.S.A.) window discriminator (mod. 121). The resulting Transistor-Transistor Logic pulses were used to trigger a Tektronix digitizing oscilloscope (model TDS 430A) for displaying and printing selected full waveforms of discriminated impulses, in order to continuously check the absence of variation of impulse morphology caused by other active neurons or local tissue movement. The raw activity signal was also digitally converted and then passed through a software window discriminator. Subsequently, raw activity digital signals together with isolated waveforms (4 ms duration for each extracted event) were displayed on-line by means of a computer monitor. Waveforms were then stored on a computer together with their temporal markers (time precision $100 \mu \mathrm{s}$ ), for off-line analysis. A ratemeter histogram of neuronal activity was continuously displayed and updated each $5 \mathrm{~s}$ on the computer screen together with a counter window, to detect variations of neuronal firing rate on-line. All computer operations were performed using the SciWorks package, version 5.0 (Datawave Technologies, Berthoud, CO, U.S.A.). The electrode was advanced using a manual hydraulic 10 microdrive (Narishige, Tokyo, Japan) until the spikes generated by a neuron were well isolated (signal to noise ratio of 3:1 or greater). Units were not added to the database if there were marked changes in amplitude or configuration of the spike or if there was early death of the cell in the course of recording. Baseline activity of each neuron was recorded for 10 min or more before acute vehicle or drug administration.

\section{Pharmacological treatment}

GLU and L-NAME were purchased from Sigma; SNOG was purchased from Tocris (TOCRIS Bioscience, Northpoint, UK). To exclude direct effects of the $\mathrm{pH}$ of drug solutions on neuronal activity, preliminary tests were performed in control rats by passing currents of the same intensity and polarity as that of ejection of drugs through barrels containing buffered-saline solutions, with $\mathrm{pH}$ and concentrations identical to drug solutions. No effects were observed. Before each test, electrical resistance of the barrels containing the drug solutions was verified in order to exclude the clogging of one or more barrels and to assure proper drug delivery. Ejection duration and inter-ejection intervals were controlled by automatic timing equipment.

For each responding neuron, GLU ejection current (40-80 nA, $30 \mathrm{~s}$ ejection time, $90 \mathrm{~s}$ inter-ejection interval time) was adjusted in order to obtain, if possible, a statistically significant increase (preferably about $50 \%$ versus basal) in neuronal spike frequency. Continuous iontophoretic application of L-NAME or SNOG was used to study the influence of local NO levels on the magnitude of neuronal responses to pulsed GLU. Nearly all neurons excited by GLU ejection underwent the iontophoretic administration of SNOG, $80 \mathrm{nA}$ for $2 \mathrm{~min}$. Some neurons were tested with SNOG at 40, 80 and $100 \mathrm{nA}$ ejection currents, in order to explore a possible current dependency of the modulation on GLU-induced responses. During SNOG continuous administration, pulsed GLU ejection (at the same current used before SNOG) was performed. After the end of SNOG ejection, if experimental conditions allowed it, new control GLU pulses were performed before and during L-NAME continuous ejection ( $5 \mathrm{~min}, 80 \mathrm{nA}$ ). SNOG and L-NAME ejection currents were selected on the basis of current-response curves previously obtained by our group (Sardo et al., 2002a,b). After the iontophoresis of a NO-active drug was terminated, recording continued until both the spontaneous firing rate and the evoked response to GLU application recovered to baseline. Only cells exhibiting recovery were included in subsequent analyses.

\section{Histology}

At the end of each experiment, the recording site was marked with Fast Green through the electrode, by using a $50 \mu \mathrm{A}$ ejection current for 15 min. Subsequently, animals were sacrificed with an overdose of pentobarbital and then transcardially perfused with saline, followed by $10 \%$ buffered formalin. Brains were removed and coronal frozen sections were cut at $50 \mu \mathrm{m}$ and stained with cresyl violet for histological verification and reconstruction of recording sites (Fig. 1). Images of sections were acquired using a Leica DFC Camera attached to a stereomicroscope (Leica Microsystems Imaging solutions Ltd, Cambridge, UK).

\section{Data analysis}

Off-line analyses of spike waveform parameters, neuronal firing rate and discharge pattern before, during and after drug administration were performed for each unit. Individual ratemeter histograms ( $5 \mathrm{~s}$ bin width) were analyzed by means of a non parametric MannWhitney U-test to detect any statistically significant treatmentrelated change in neuronal firing. To analyze L-NAME- and SNOGinduced effects, neurons were considered responsive if changes were significant (probability level $\mathrm{P}<0.05$ ) for at least six consecutive bins, the first of which was labeled as the onset of a response. For each neuron, in order to analyze the effects produced by each application of 


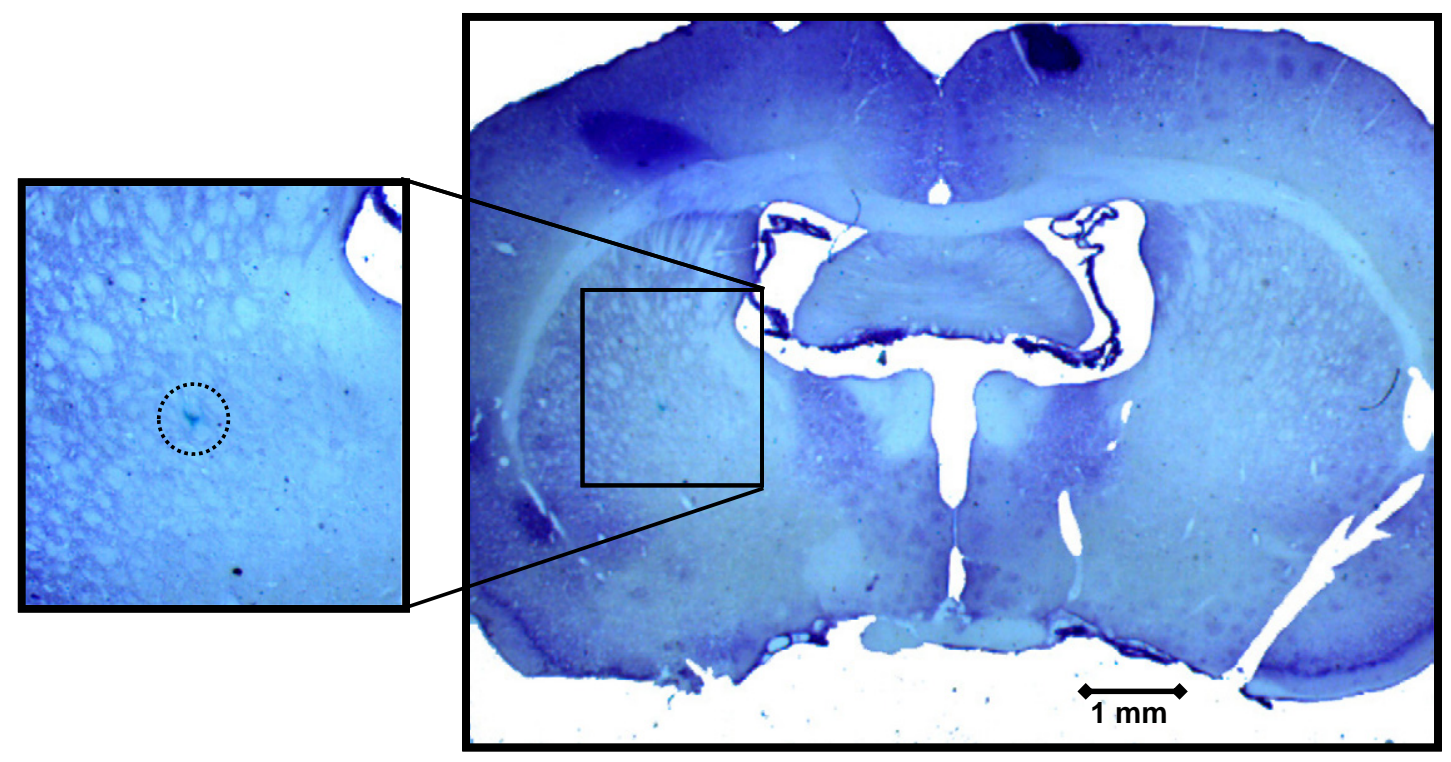

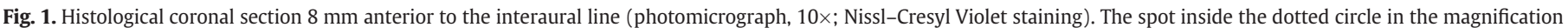
$(16 \times)$ inlet shows a recording site in the globus pallidus.

GLU in cycling mode ejection, a Mann-Whitney U-test was performed to compare the firing rate during drug administration ( 6 bins) with the baseline activity calculated during a control period of $60 \mathrm{~s}$ (12 bins) before treatment. Inter-spike interval histograms (ISIHs) were calculated for each unit to analyze the discharge pattern either in basal conditions or during and after iontophoretic pharmacological treatment. The basal discharge pattern was evaluated for $5 \mathrm{~min}$. ISIH analysis was performed using a $1 \mathrm{~ms}$ bin width, and the modes of intervals, mean intervals, standard deviations (SD) of the mean intervals and coefficients of variation $(\mathrm{CV}=\mathrm{SD} /$ mean interval) of intervals were calculated.

Repeated measures analysis of variance (ANOVA) was used to compare GLU-induced response magnitudes obtained in basal conditions versus the ones observed during administration of NOactive drugs. Comparisons between frequencies were performed by means of a $\chi^{2}$ test. For all statistical tests used, the null hypothesis was rejected at a $P$ lower than 0.05 . If not otherwise indicated, all results are expressed as means \pm SD.

\section{Results}

Recorded cells within the GP

The bioelectric activity of 68 histologically verified spontaneously active GP neurons was recorded. As already found in previous research (Sardo et al, 2002a), first order ISIH analysis allowed us to discriminate between two different neuronal firing patterns: 39 neurons $(57.35 \%)$ showed a regular firing with a symmetric unimodal peak in the ISIH, whereas 29 (42.65\%) showed an irregular firing with no unimodal peak. All recorded impulses had biphasic negativepositive waveform (Table 1). The comparison between the waveform parameters of regularly versus irregularly discharging neurons did not show statistically significant difference. A $\chi^{2}$ analysis revealed that none of the above-reported characteristics of action potentials or discharge patterns influenced significantly the neuronal responsiveness to the application of any drug (Table 2 ).

\section{Effect of GLU pulsed administration on GP neurons}

All neurons were tested with two pulses of GLU (ejection current ranging from 40 to $80 \mathrm{nA}$, as described in the Material and methods section) separated by a $90 \mathrm{~s}$ inter-pulse interval, in order to exclude that the effect of the first pulse could influence the following one; only the neurons responding to both pulses were considered responsive to treatment. Among tested neurons, 57 cells displayed a significant increase of their discharge rate during GLU ejection (mean magnitude $+41.90 \pm 27.16 \%$ ), whereas 11 did not show significant responses. All responding cells were tested with at least one NO-active drug, as described in the following paragraphs.

\section{Effect of GLU and SNOG iontophoretic co-administration on GP neurons}

Fifty-two GP neurons were also tested with the iontophoretic application of SNOG ( $80 \mathrm{nA}$ for $2 \mathrm{~min}$ ), which induced statistically significant changes in the firing rate of 43 neurons. In particular, 39 cells were excited during SNOG ejection $(+49.79 \pm 28.07 \%)$, whereas 4 neurons were inhibited $(-41.24 \pm 19.23 \%)$ and 9 cells did not modify their discharge. No changes in morphology of ISIHs were observed during drug administration. The firing rate of responsive cells returned to the control level immediately after the end of the drug ejection. Excitatory, inhibitory or null responses were not differently distributed between regularly and irregularly discharging neurons (Table 2). Moreover, the spontaneous discharge pattern of nonresponsive neurons was not modified during SNOG administration. Furthermore, no spatial segregation of either responding or not responding cells was evidenced.

During SNOG ejection, if the neuronal discharge was stable for at least $1 \mathrm{~min}$, pulsed GLU ejection was performed at the same current used before. Statistically significant modifications of GLU-evoked responses were observed during SNOG continuous ejection (Table 2). In particular, a large incidence of increased GLU-induced responses magnitude was observed among the neurons previously excited by

Table 1

Spontaneous activity of GP units: electrophysiological features of neuronal discharge patterns and waveforms.

\begin{tabular}{|c|c|c|c|c|c|}
\hline $\begin{array}{l}\text { Neuronal } \mathrm{n} \\
\text { firing } \\
\text { pattern }\end{array}$ & $\begin{array}{l}\text { Mean firing } \\
\text { rate }(\mathrm{Hz})\end{array}$ & $\begin{array}{l}\text { Mode of } \\
\text { interspike } \\
\text { intervals } \\
(\mathrm{ms})\end{array}$ & $\begin{array}{l}\text { Mean } \\
\text { interspike } \\
\text { interval } \\
(\mathrm{ms})\end{array}$ & $\begin{array}{l}\text { Mean } \\
\text { spike } \\
\text { duration } \\
(\mathrm{ms})\end{array}$ & $\begin{array}{l}\text { Mean peak } \\
\text { to peak } \\
\text { amplitude } \\
(\mathrm{mV})\end{array}$ \\
\hline
\end{tabular}

$\begin{array}{lllllll}\text { Regular } & 39 & 28.42 \pm 12.67 & 27.16 \pm 13.41 & 37.12 \pm 14.15 & 1.80 \pm 0.35 & 1.21 \pm 0.45\end{array}$

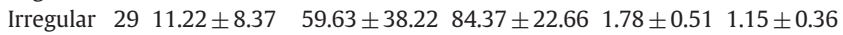


Table 2

SNOG effects on GP units: relationships between neuronal drug-responsiveness and basal firing.

\begin{tabular}{|c|c|c|c|c|c|c|c|c|c|}
\hline $\begin{array}{l}\text { SNOG } \\
\text { effect on } \\
\text { basal firing }\end{array}$ & $\mathrm{n}$ & $\begin{array}{l}\mathrm{n} \\
\text { reg }^{\mathrm{a}}\end{array}$ & $\begin{array}{l}\mathrm{n} \\
\text { irreg }^{\mathrm{b}}\end{array}$ & $\begin{array}{l}\chi^{2} \text { test } \\
(D F=2)\end{array}$ & $\begin{array}{l}\text { SNOG } \\
\text { effect } \\
\text { on GLU } \\
\text { response } \\
\text { magnitude }\end{array}$ & $\mathrm{n}$ & $\begin{array}{l}\mathrm{n} \\
\text { reg }^{\mathrm{a}}\end{array}$ & $\begin{array}{l}\mathrm{n} \\
\text { irreg }^{\mathrm{b}}\end{array}$ & $\begin{array}{l}\chi^{2} \text { test } \\
(\mathrm{DF}=2)\end{array}$ \\
\hline \multirow[t]{3}{*}{ Increase } & 39 & 21 & 18 & $\chi^{2} 1.040$ & + & 34 & 19 & 15 & $\chi^{2} 0.627$ \\
\hline & & & & & - & 5 & 2 & 3 & \\
\hline & & & & & $=$ & 0 & 0 & 0 & \\
\hline \multirow[t]{3}{*}{ Decrease } & 4 & 3 & 1 & & + & 1 & 1 & 0 & \\
\hline & & & & & - & 0 & 0 & 0 & \\
\hline & & & & & $=$ & 3 & 2 & 1 & \\
\hline \multirow[t]{3}{*}{ None } & 9 & 4 & 5 & Р 0.59 & + & 4 & 1 & 3 & Р 0.731 \\
\hline & & & & & - & 0 & 0 & 0 & \\
\hline & & & & & $=$ & 5 & 3 & 2 & \\
\hline \multirow[t]{3}{*}{ Tot } & 52 & 28 & 24 & & Tot + & 39 & 21 & 18 & \\
\hline & & & & & Tot - & 5 & 2 & 3 & \\
\hline & & & & & Tot $=$ & 8 & 5 & 3 & \\
\hline
\end{tabular}

\footnotetext{
a Regularly discharging neurons.

b Irregularly discharging neurons.
}

SNOG administration (mean $68.93 \pm 49.79 \%$ vs $38.99 \pm 26.57 \%$, $\mathrm{F}=11.231, \mathrm{P}=0.002$; Fig. 2). Increase or reduction of GLU-induced response magnitude during SNOG ejection was not dependent on the magnitude of the control response to GLU (Fig. 3). Interestingly, even among the 9 cells not directly excited by SNOG ejection, modulation of GLU-induced responses magnitude was observed in 4 neurons showing statistically significant increase $(85.43 \pm 61.42 \%$ vs $58.11 \pm 50.82 \%$, $\mathrm{F}=11.684, \mathrm{P}=0.0419)$, whereas 5 exhibited responses not significantly modulated (Table 2 ).

Seventeen neurons responding to SNOG ejection at $80 \mathrm{nA}$ were also tested with SNOG at 40 and $100 \mathrm{nA}$ currents, in order to explore for a possible current dependency of the SNOG induced modulation of GLU excitation. Repeated measurement of ANOVA ( $F=5.39, P=$ 0.0028 ) showed significant increase of the mean response magnitude obtained at both $80 \mathrm{nA}(\mathrm{D} \%=42.46, \mathrm{P}=0.0323)$ and $100 \mathrm{nA}$ $(\mathrm{D} \%=73.39, \mathrm{P}=0.0004)$ ejection currents versus values obtained before SNOG (Fig. 4). Furthermore, the GLU-induced responses observed during SNOG $100 \mathrm{nA}$ ejection were significantly greater than those obtained with SNOG $40 \mathrm{nA}$ ejection currents ( $\mathrm{D} \%=54.19$, $\mathrm{P}=0.0071)$.

Effect of GLU and L-NAME iontophoretic co-administration on GP neurons

Fourteen out of the GP neurons excited by pulsed GLU ejection also received the iontophoretic application of L-NAME at $80 \mathrm{nA}$ for $5 \mathrm{~min}$. Nine among these cells had been already tested with SNOG and GLU co-administration (see next paragraph for details). The discharge activity of 10 cells was significantly reduced by drug application $(-34.67 \pm 20.41 \%)$, whereas the firing of 4 cells was unaffected. The discharge frequency of responsive cells returned to control level after the end of drug ejection. No changes in morphology of ISIHs were observed during current administration. Inhibitory or null responses were not differently distributed between regularly and irregularly discharging neurons. Furthermore, the spontaneous discharge pattern of nonresponsive neurons was not modified by L-NAME administration. Finally, no spatial segregation of either responding or not responding cells was evidenced.

In all neurons pulsed GLU was iontophoretically co-administered when the effect of L-NAME on the neuronal firing rate was stable for at least $1 \mathrm{~min}$. All tested neurons showed L-NAME-induced modification of responses to GLU administration; in particular, the 10 cells inhibited by L-NAME showed either a complete abolition $(n=3)$ or a statistically significant reduction of the magnitude of GLU-induced responses $(36.49 \pm 25.23 \%$ vs $63.08 \pm 53.40 \%, F=5.512, P=0.0468$;

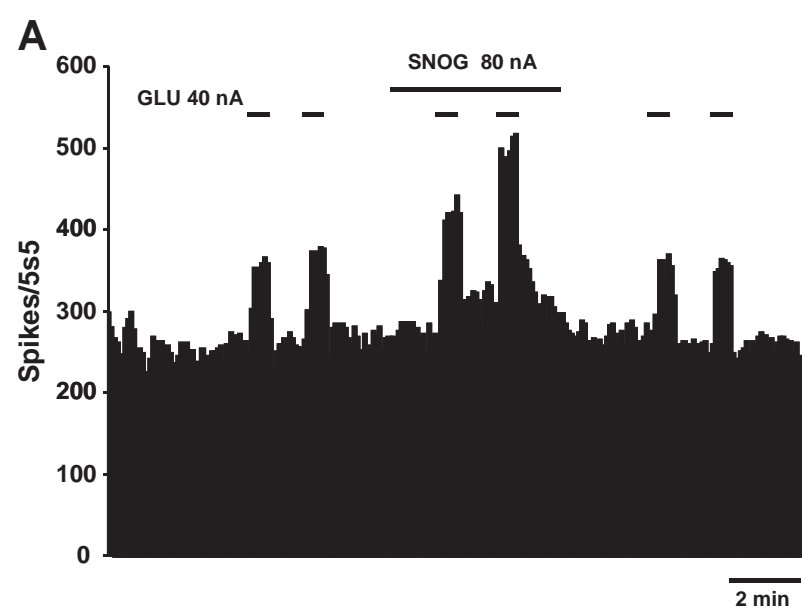

B

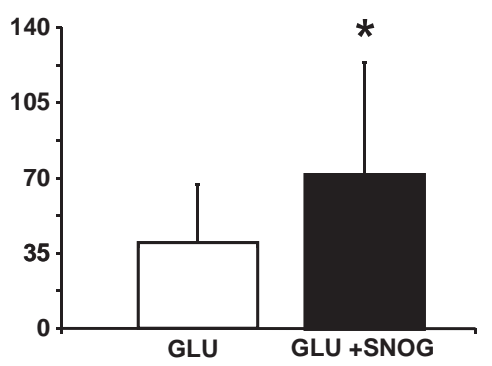

Fig. 2. SNOG-GLU interaction. A: Representative rate-meter histogram (bin width $5 \mathrm{~s}$ ) showing increased magnitude of GLU-evoked responses during continuous ejection of SNOG. B: Bar histogram showing mean $( \pm S D)$ percent magnitude of GLU-evoked responses before (white column) and during (ruled column) SNOG administration ( *statistically significant at $\mathrm{P}<0.05$ ).

Fig. 5). Albeit observable ( $-52.56 \%)$, the reduction in magnitudes did not reach statistical significance in the 4 neurons previously unaffected by L-NAME ejection $(\mathrm{F}=4.638, \mathrm{P}=0.0976)$.

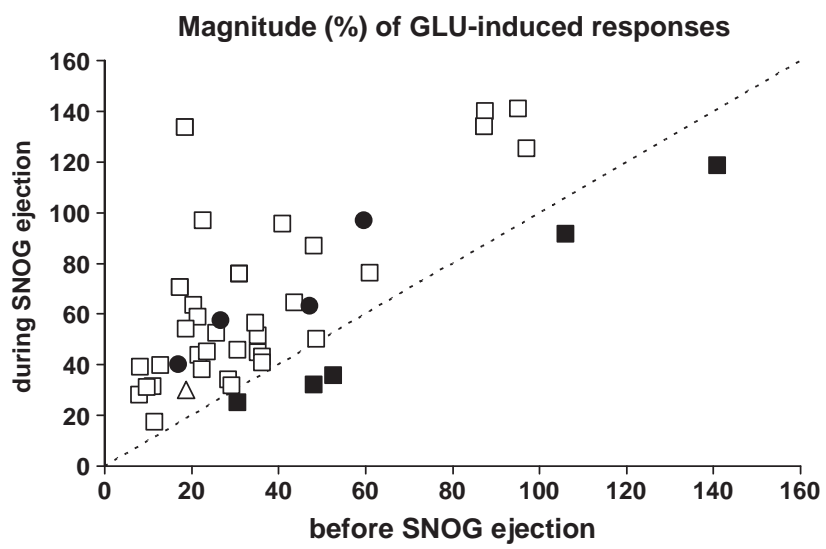

Fig. 3. SNOG-GLU interaction. Each point of the figure plots, for each neuron, the magnitude of the GLU-induced response during SNOG ejection ( $80 \mathrm{nA}$ ) against the magnitude of the response to GLU before SNOG administration. The dotted line separates the area of increased response magnitude from the one of decreased magnitude. Boxes: cells excited by SNOG alone (white: increased magnitude; black: decreased magnitude). Circles: cells indifferent to SNOG alone. Triangle: cell inhibited by SNOG alone. Only the cells displaying SNOG-induced modulation of GLU-induced responses are represented. 


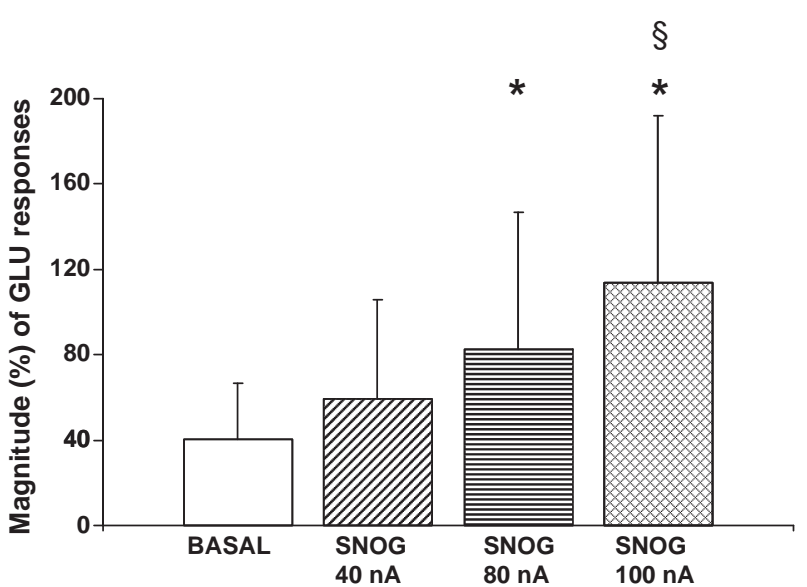

Fig. 4. SNOG-GLU interaction. Bar histogram showing the effect of SNOG at different ejection currents on GLU-induced responses. Each bars represents mean \pm standard deviation ( ${ }^{*}$ statistically significant at $\mathrm{P}<0.05$ versus basal; $\S$ statistically significant at $\mathrm{P}<0.05$ versus $40 \mathrm{nA}$ ).

Neurons treated with both GLU-SNOG and GLU-L-NAME co-administrations

Nine neurons were treated with both co-administration protocols. With the exception of one neuron excited by SNOG and inhibited by L-NAME ejection, the cells responding to SNOG $(n=5)$ with an overt change in basal activity did not display responses to L-NAME administration, and vice-versa. One neuron did not respond to any drug. Interestingly, even if no overt changes in basal activity were observed during the administration of a NO-active drug, all neurons displayed changes in magnitudes of GLU-induced responses during both treatments. In fact, all neurons but one exhibited increased magnitude of responses to GLU ejection during SNOG administration $(76.13 \pm 46.56 \%$ vs $52.65 \pm 39.95 \%, F=13.756, P=0.0076)$ and reduced magnitudes during L-NAME treatment $(43.54 \pm 27.20$ vs $79.16 \pm 22.72 \%, \mathrm{~F}=6.454, \mathrm{P}=0.0386)$.

\section{Discussion}

NO is a versatile gaseous molecule, able to modulate both the neuronal excitability and the release of neurotransmitters in many structures of the CNS of mammalians (Cudeiro et al., 1997; Shaw and Salt, 1997; Ferraro et al., 1999; Trabace and Kendrick, 2000; Prast and Philippu, 2001; Ahern et al., 2002; Li et al., 2004; Garthwaite, 2008). Clear NO-mediated actions have been shown in the BG (Cox and Johnson, 1998; Calabresi et al., 1999; Centonze et al., 2001): in this regard, strong modulatory effects exerted by NO-active drugs on the bioelectric activity of striatal, pallidal, subthalamic and nigral cells have been recently demonstrated (Sardo et al., 2002a,b, 2003, 2006a,b; Carletti et al., 2009), as well as a marked influence of NOactive drugs on GABA- and GLU-evoked responses in the STN (Sardo et al., 2009).

\section{NO-dependent modulation of neuronal responses to GLU}

This study, showing modulation of GLU-induced responses of GP neurons through the manipulation of the nitrergic metabolic system, extends our previous observation that the NOS inhibitor L-NAME reduces the discharge activity and, conversely, that NO donor molecules increase the firing rate of GP cells (Sardo et al, 2002a). New information was obtained by iontophoretically co-administering NO-active drugs with GLU: in fact, the administration of L-NAME significantly damped the glutamate-driven excitatory effect down, while the ejection of SNOG significantly intensified it. The analysis of

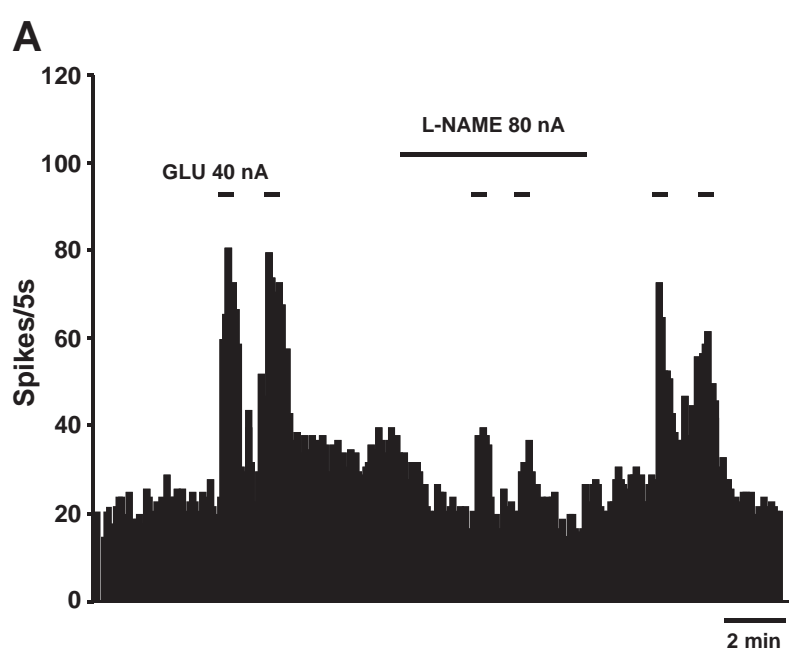

B

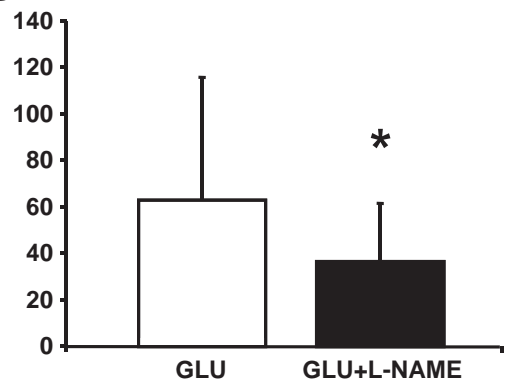

Fig. 5. L-NAME-GLU interaction. A: Representative rate-meter histogram (bin width $5 \mathrm{~s}$ ) showing decreased magnitude of GLU-evoked responses during continuous ejection of L-NAME. B: Bar histogram showing mean $( \pm S D)$ percent magnitude of GLU-evoked responses before (white column) and during (ruled column) L-NAME administration (*statistically significant at $\mathrm{P}<0.05$ ).

the magnitude of GLU-induced responses during the administration of SNOG at different currents in the same neurons showed a clear current dependency of the excitatory modulation induced by the NO donor. Furthermore, a very few number of cells displaying a reduction of the magnitude of GLU-dependent responses during SNOG administration was observed, but no evident relationship was showed between the sign of the SNOG-induced modulation and the magnitude of responses to GLU before SNOG administration. Interestingly, the modulation induced by NO-active drugs on the magnitude of GLU-induced neuronal responses was not necessarily linked to a direct, overt effect of the NO donor or the nNOS inhibitor on the spontaneous neuronal discharge activity. All recorded cells were characterized by spontaneous activity and probably they functionally represent projection neurons (Nambu and Llinas, 1997; Cooper and Stanford, 2000). Despite the different neuronal firing patterns (regularly and irregularly discharging units), already showed by previous studies (Ni et al., 2000; Sardo et al, 2002a), no patternrelated heterogeneous responses to pharmacological treatments were observed.

Possible mechanisms involved in the NO-dependent modulation of responses to GLU

The data suggest that the previously observed NO-induced modulation of the bioelectric activity of GP cells could be obtained, to some extent, by influencing the glutamatergic neurotransmission. Evidences of a fine control exerted by other transmitters or neuromodulators on the glutamatergic transmission have already been highlighted in the GP: e.g., dopamine was suggested to have a role in 
processing cortical information in the indirect pathway through $\mathrm{D}_{1}$ receptors (Hernandez et al., 2006, 2007); further on, the peptidergic neuromodulator neurotensin selectively enhances GLU transmission in the GP (Chen et al., 2006). On the other side, several studies showed a modulatory role of NO on both the neuronal excitability and the release of GLU (Ohkuma and Katsura, 2001; Prast and Philippu, 2001). Our present results suggest the NO as a further modulator of GLU transmission in the GP.

Although NO mainly acts through the activation of the soluble form of guanylyl cyclase (sGC), which, in turn, produces the secondmessenger cyclic guanosine monophosphate (cGMP), modulated by cGMP-regulated phosphodiesterases and downstream acting on cGMP-dependent protein kinases (PKG) or cyclic nucleotide-gated (CNG) ion channels (Kleppisch and Feil, 2009), the evidenced NOinduced modulation could also be potentially exerted through different mechanisms. Although this specific issue remains to be experimentally tested, our previous data obtained in both the STN and the striatum, as well as some considerations on the distribution of drug-induced effects among neurons, lead us to hypothesize a role for cGMP in some of the observed effects. Moreover, it must be noted that, with some sparse exception, no co-localization of nNOS and SGC has been observed in the same neurons (De Vente et al., 1998). From this point of view, taking into consideration the NO/cGMP pathway, a locally applied NO donor (e.g. SNOG) could be potentially able to modulate the activity of a cell at least containing the SGC, whereas an iontophoretically administered NOS inhibitor, in this case L-NAME, necessarily could only influence the activity of the few neurons containing both the nNOS and the SGC. This consideration leads to forecast higher numbers of neurons responding to locally applied NO donors than to nNOS inhibitors, if only the cGMP pathway is the one involved in the observed effects. In fact, our previous studies, exploring changes in spontaneous neuronal discharge induced by iontophoretically administered NO donors and nNOS inhibitors, always showed much more responses to NO donors than to nNOS inhibitors, as well as only sporadically occurring responses of the same cell to both kinds of molecules. It must be noted that, even in the present study, when neurons were tested with both NO-active drugs at different times, the great majority of cells responded with a change in basal discharge to only one treatment. However, additional considerations have to be made in order to explain the observed modulation of GLU-induced responses. In fact, it must be considered that, although the overt excitatory (to SNOG) or inhibitory (to LNAME) responses to NO-active drugs always remained separated in all neurons treated with both drugs, at the same time all of these cells showed clear, statistically significant modulation exerted by both NOactive drugs on the neuronal responses to GLU ejection, suggesting the possible involvement of others effectors than sGC. Thus, the observed effects could be the result of cGMP-independent pathways such as direct protein nitrosylation by NO or peroxynitrite formation and subsequent protein nitration and oxidation (Ahern et al., 2002; Yoshida et al., 2006; Zhou et al., 2008). Moreover, it must be observed that, even if a direct effect of the NO-active drug was not evident on the basal neuronal discharge, often (always, in the neurons tested with both drugs) a significant effect was observed on the magnitude of GLU-induced responses. With this perspective, it is noteworthy the close relationship between the NMDA receptor (NMDAR) and the NOS, as well as their possible downstream feedback interactions; for example, S-nitrosylation of NMDAR was proposed as a modulating mechanism to escape from receptor overactivation (Choi et al., 2000). Furthermore, a sGC-PKG dependent control exerted by NO on the function of the AMPA receptor (AMPAR) has been suggested (McMahon and Ponomareva, 1996). Moreover, recent studies hypothesize the involvement of NO in long term potentiation (LTP) depending on metabotropic GLU receptors (mGluR) (Anwyl, 2009). All three types of GLU receptors are expressed in GP (Kaneda et al., 2007) so representing potential targets for nitrergic action.
Furthermore, an indirect involvement of GABAergic transmission cannot be ruled out in the interpretation of our data; in fact, the possible interaction between NO and GABA receptors must be taken into consideration, as suggested by some evidence about the depression induced by both cGMP and NO donors on GABAreceptor-mediated responses (Wexler et al., 1998); in this regard, we previously observed NO-mediated modulation of GABA neurotransmission in STN, in agreement with the idea that nitrergic intervention could represent a negative modulator in GABAergic synapses (Sardo et al., 2009).

Finally, it has been shown that NO can increase cerebral blood flow (Prado et al., 1992) by releasing vascular smooth muscle cells (Moncada et al., 1991). Therefore, the microiontophoretic application of SNOG or L-NAME could influence the microvascular tone by interfering with NO formation. However, it seems unlikely that the effects of these compounds on GP neuronal activity might be secondary to modifications in local microcirculation, inasmuch as recent data show that the microiontophoretic application of different NO-modulating compounds in the visual cortex do not modify the cortical blood flow measured with laser-Doppler flow meter (Kara and Friedlander, 1999). Moreover, our hypothesis that the effect of NO-acting drugs on GP neuronal activity is primarily attributable to a direct effect on neuronal targets is corroborated by the finding that topical application of L-arginine, the endogenous substrate of the synthesis of NO, induces only a slight dilatation of pial arterioles in normotensive rats (Riedel et al., 1995).

\section{Implication for GP function in BG circuits}

Then, the observed NO-induced modulation of the intensity of excitatory responses to GLU could be due either to a reinforcement of GLU transmission or to an interference with GABA receptors function. In fact, intrinsic NO-producing interneurons exist in the GP, which could have a role in modulating output cells' activity; the synaptic terminals of these NO-producing neurons are anatomically close to both striatal GABAergic and subthalamic glutamatergic endings (Bolan et al., 2000). Thus, the suggested NO-mediated control could represent a mechanism able to regulate the flow of glutamatergic inputs to the GP arising from several CNS regions; out of these, the STN, through its reciprocal connections with GP, constitutes a structure of primary importance. According to the standard models of BG processing, GP and STN are involved together in the indirect pathway (Smith et al, 1998); they form a key network, characterized by pacemaker activity and a powerful impact on the BG output (Plenz and Kitai, 1999; Bevan et al., 2002). The GP gives rise to massive topographically organized GABAergic projections that terminate throughout the entire extent of the STN; in turn, glutamatergic STN neurons project back to GP playing crucial roles in both the maintenance of the firing activity and the generation of firing patterns (Kita et al., 2004). Moreover, STN relays to GP the activity driven by inputs directly arising from motor-related areas of the cerebral cortex (Nambu et al., 2000). A functional interaction between the nitrergic, GABAergic and glutamatergic neurotransmitter systems has been recently shown in the STN, suggesting a modulatory role exerted by NO availability on the GABA- and GLU-dependent changes of STN neuron discharge activity (Sardo et al., 2009). Furthermore, our present data show qualitatively similar effects of NO-active drugs on the GLU-evoked responses in the GP. In this framework, NO could play a modulatory role on both the GP neuronal activity and the reciprocal interactions of GP/STN network, in either normal conditions or pathophysiological states. In this regard, it is interesting to mention that an increase of NOS mRNA expression in the GP was observed in patients with Parkinson's disease (PD; Eve et al., 1998). Altered local level of NO could have effect on both the basal neuronal activity and the modulation of classical neurotransmission, leading to abnormal activity patterns in GPe neurons, such as bursty or synchronous 
rhythmic activity, which are thought to have far-reaching consequences for BG function and motor control (Bolam et al., 2000); moreover, altered synchronized and oscillatory activity of the GP/STN network, a central pacemaker likely responsible for synchronized oscillatory activity in the normal and pathological BG (Plenz and Kitai, 1999), could result in a less efficient coding of information by BG and, in turn, could contribute to the symptoms of Parkinson's disease (Gatev et al., 2006).

\section{Conclusions}

The magnitude of glutamate-induced excitatory effects was significantly decreased by L-NAME, whereas it was increased by SNOG. Our results raise the idea that NO cerebral levels could represent a tool to modulate the glutamatergic neurotransmission in the GP, so affecting the BG output either in normal or pathological conditions. In particular, the suggested NO-mediated control could have a pivotal role in the regulation of the relationship between GP/STN, by acting on both their reciprocal inhibitory/excitatory connections.

\section{Conflict of interest statement}

No competing interests.

\section{References}

Ahern GP, Klyachko VA, Jackson MB. cGMP and S-nitrosylation: two routes for modulation of neuronal excitability by NO. Trends Neurosci 2002:25(10):510-7.

Anwyl R. Metabotropic glutamate receptor-dependent long-term potentiation. Neuropharmacology 2009;56(4):735-40.

Bevan MD, Magill PJ, Terman D, Bolam JP, Wilson CJ. Move to the rhythm: oscillations in the subthalamic nucleus-external globus pallidus network. Trends Neurosci 2002;25(10):525-31

Bolam JP, Hanley JJ, Booth PA, Bevan MD. Synaptic organisation of the basal ganglia. J Anat 2000;196(4):527-42.

Bolan EA, Gracy KN, Chan J, Trifiletti RR, Pickel VM. Ultrastructural localization of nitrityrosine within the caudate-putamen nucleus and the globus pallidus of normal rat brain. J Neurosci 2000;20:4798-808.

Calabresi P, Gubellini P, Centonze D, Sancesario G, Morello M, Giorgi M, et al. A critical role of the nitric oxide/cGMP pathway in corticostriatal long-term depression. J Neurosci 1999;19(7):2489-99.

Carletti F, Ferraro G, Rizzo V, D'Agostino S, Lonobile G, Sardo P. Nitric oxide- and cGMPactive compounds affect the discharge of substantia nigra pars reticulata neurons: in vivo evidences in the rat. J Neural Transm 2009;116(5):539-49.

Centonze D, Pisani A, Bonsi P, Giacomini P, Bernardi G, Calabresi P. Stimulation of nitric oxide-cGMP pathway excites striatal cholinergic interneurons via protein kinase $G$ activation. J Neurosci 2001;21(4):1393-400.

Chen L, Yung KK, Yung WH. Neurotensin selectively facilitates glutamatergic transmission in globus pallidus. Neuroscience 2006;141(4):1871-8.

Chen L, Yung KK, Chan YS, Yung WH. 5-HT excites globus pallidus neurons by multiple receptor mechanisms. Neuroscience 2008;151(2):439-51.

Choi YB, Tenneti L, Le DA, Ortiz J, Bai G, Chen HS, et al. Molecular basis of NMDA receptor-coupled ion channel modulation by S-nitrosylation. Nat Neurosci 2000;3 (1):15-21.

Conn PJ, Battaglia G, Marino MJ, Nicoletti F. Metabotropic glutamate receptors in the basal ganglia motor circuit. Nat Rev Neurosci 2005;6(10):787-98.

Cooper AJ, Stanford IM. Electrophysiological and morphological characteristics of three subtypes of rat globus pallidus neurone in vitro. J Physiol 2000;527(2):291-304.

Cox BA, Johnson SW. Nitric oxide facilitates N-methyl-D-aspartate-induced burst firing in dopamine neurons from rat midbrain slices. Neurosci Lett 1998;255(3):131-4.

Cudeiro J, Rivadulla C, Rodríguez R, Grieve KL, Martínez-Conde S, Acuña C. Actions of compounds manipulating the nitric oxide system in the cat primary visual cortex. J Physiol 1997;504(2):467-78.

De Vente J, Hopkins DA, Markerink-Van Ittersum M, Emson PC, Schmidt HH, Steinbusch HW. Distribution of nitric oxide synthase and nitric oxide-receptive, cyclic GMPproducing structures in the rat brain. Neuroscience 1998;87(1):207-41.

Eve DJ, Nisbet AP, Kingsbury AE, Hewson EL, Daniel SE, Lees AJ, et al. Basal ganglia neuronal nitric oxide synthase mRNA expression in Parkinson's disease. Brain Res Mol Brain Res 1998;63(1):62-71.

Ferraro G, Montalbano ME, La Grutta V. Nitric oxide and glutamate interaction in the control of cortical and hippocampal excitability. Epilepsia 1999;40(7):830-6.

Garthwaite J. Concepts of neural nitric oxide-mediated transmission. Eur J Neurosci 2008;27(11):2783-802.

Gatev P, Darbin O, Wichmann T. Oscillations in the basal ganglia under normal conditions and in movement disorders. Mov Disord 2006;21(10):1566-77.

Hazrati LN, Parent A. Convergence of subthalamic and striatal efferents at pallidal level in primates: an anterograde double-labeling study with biocytin and PHA-L. Brain Res 1992;569(2):336-40.
Hernandez A, Ibañez-Sandoval O, Sierra A, Valdiosera R, Tapia D, Anaya V, et al. Control of the subthalamic innervation of the rat globus pallidus by D2/3 and D4 dopamine receptors. J Neurophysiol 2006;96(6):2877-88.

Hernandez A, Sierra A, Valdiosera R, Floran B, Erlij D, Aceves J. Presynaptic D1 dopamine receptors facilitate glutamatergic neurotransmission in the rat globus pallidus. Neurosci Lett 2007;425(3):188-91.

Kaneda K, Kita T, Kita H. Repetitive activation of glutamatergic inputs evokes a longlasting excitation in rat globus pallidus neurons in vitro. J Neurophysiol 2007;97 (1):121-33.

Kara P, Friedlander MJ. Arginine analogs modify signal detection by neurons in the visual cortex. J Neurosci 1999;19:5528-48.

Kita H, Nambu A, Kaneda K, Tachibana Y, Takada M. Role of ionotropic glutamatergic and GABAergic inputs on the firing activity of neurons in the external pallidum in awake monkeys. J Neurophysiol 2004;92(5):3069-84.

Kleppisch T, Feil R. cGMP signalling in the mammalian brain: role in synaptic plasticity and behaviour. Handb Exp Pharmacol 2009;191:549-79.

Lee CR, Tepper JM. Basal ganglia control of substantia nigra dopaminergic neurons. J Neural Transm 2009;73:71-90.

Li DP, Chen SR, Finnegan TF, Pan HL. Signalling pathway of nitric oxide in synaptic GABA release in the rat paraventricular nucleus. J Physiol 2004;554(1):100-10.

McMahon DG, Ponomareva LV. Nitric oxide and cGMP modulate retinal glutamate receptors. J Neurophysiol 1996;76(4):2307-15.

Moncada S, Palmer RM, Higgs EA. Nitric oxide: physiology, pathophysiology, and pharmacology. Pharmacol Rev 1991;43:109-42.

Mouroux M, Hassani OK, Feger J. Electrophysiological and Fos immunohistochemical evidence for the excitatory nature of the parafascicular projection to the globus pallidus. Neuroscience 1997;81(2):387-97.

Naito A, Kita $\mathrm{H}$. The cortico-pallidal projection in the rat: an anterograde tracing study with biotinylated dextran amine. Brain Res 1994;653(1-2):251-7.

Nambu A, Llinas R. Morphology of globus pallidus neurons: its correlation with electrophysiology in guinea pig brain slices. J Comp Neurol 1997;377(1):85-94.

Nambu A, Tokuno H, Hamada I, Kita H, Imanishi M, Akazawa T, et al. Excitatory cortical inputs to pallidal neurons via the subthalamic nucleus in the monkey. J Neurophysiol 2000;84(1):289-300.

Ni Z, Bouali-Benazzouz R, Gao D, Benabid A, Benazzouz A. Changes in the firing pattern of globus pallidus neurons after the degeneration of nigrostriatal pathway are mediated by the subthalamic nucleus in the rat. Eur J Neurosci 2000;12(12): 4338-44.

Ohkuma S, Katsura M. Nitric oxide and peroxynitrite as factors to stimulate neurotransmitter release in the CNS. Prog Neurobiol 2001;64(1):97-108.

Parent A, Hazrati LN. Functional anatomy of the basal ganglia. II. The place of subthalamic nucleus and external pallidum in basal ganglia circuitry. Brain Res Brain Res Rev 1995;20(1):128-54.

Parent A, Sato F, Wu Y, Gauthier J, Levesque M, Parent M. Organization of the basal ganglia: the importance of axonal collateralization. Trends Neurosci 2000;23(10): S20-7.

Paxinos G, Watson C. The rat brain in stereotaxic coordinates. San Diego: Academic Press; 1998.

Plenz D, Kitai ST. A basal ganglia pacemaker formed by the subthalamic nucleus and external globus pallidus. Nature 1999;400(6745):677-82

Prado R, Watson BD, Kuluz J, Dietrich WD. Endothelium derived nitric oxide synthase inhibition. Effects on cerebral blood flow, pial artery diameter, and vascular morphology in rats. Stroke 1992;23:1118-23.

Prast H, Philippu A. Nitric oxide as modulator of neuronal function. Prog Neurobiol 2001;64(1):51-68

Riedel MW, Anneser F, Haberl RL. Different mechanisms of L-arginine induced dilation of brain arterioles in normotensive and hypertensive rats. Brain Res 1995;671:21-6.

Rodrigo J, Springall DR, Uttenthal O, Bentura ML, Abadia-Molina F, Riveros-Moreno V, et al. Localization of nitric oxide synthase in the adult rat brain. Phil Trans Roy Soc Lond B Biol Sci 1994;345(1312):175-221.

Rouse ST, Marino MJ, Bradley SR, Awad H, Wittmann M, Conn PJ. Distribution and roles of metabotropic glutamate receptors in the basal ganglia motor circuit: implications for treatment of Parkinson's disease and related disorders. Pharmacol Ther 2000;88(3):427-35.

Sardo P, Ferraro G, Di Giovanni G, Galati S, La Grutta V. Influence of nitric oxide on the spontaneous activity of globus pallidus neurones in the rat.J Neural Transm 2002a;109 (11):1373-89.

Sardo P, Ferraro G, Di Giovanni G, Galati S, La Grutta V. Inhibition of nitric oxide synthase influences the activity of striatal neurons in the rat. Neurosci Lett 2002b;325(3):179-82.

Sardo P, Ferraro G, Di Giovanni G, La Grutta V. Nitric oxide-induced inhibition on striatal cells and excitation on globus pallidus neurons: a microiontophoretic study in the rat. Neurosci Lett 2003;343(2):101-4.

Sardo P, Ferraro G, Carletti F, D'Agostino S, La Grutta V. The discharge of subthalamic neurons is modulated by inhibiting the nitric oxide synthase in the rat. Neurosci Lett 2006a;396(3):252-6.

Sardo P, Carletti F, D'Agostino S, Rizzo V, Ferraro G. Effects of nitric oxide-active drugs on the discharge of subthalamic neurons: microiontophoretic evidence in the rat. Eur J Neurosci 2006b;24(7):1995-2002.

Sardo P, Carletti F, D'Agostino S, Rizzo V, La Grutta V, Ferraro G. Intensity of GABAevoked responses is modified by nitric oxide-active compounds in the subthalamic nucleus of the rat: a microiontophoretic study. J Neurosci Res 2009;87 (10):2340-50.

Sato F, Lavallee P, Levesque M, Parent A. Single-axon tracing study of neurons of the external segment of the globus pallidus in primate. J Comp Neurol 2000;417(1): $17-31$. 
Shaw PJ, Salt TE. Modulation of sensory and excitatory amino acid responses by nitric oxide donors and glutathione in the ventrobasal thalamus of the rat. Eur J Neurosci 1997;9(7):1507-13.

Smith Y, Bevan MD, Shink E, Bolam JP. Microcircuitry of the direct and indirect pathways of the basal ganglia. Neuroscience 1998;86(2):353-87.

Trabace L, Kendrick KM. Nitric oxide can differentially modulate striatal neurotransmitter concentrations via soluble guanylate cyclase and peroxynitrite formation. J Neurochem 2000;75(4):1664-74.

Wexler EM, Stanton PK, Nawy S. Nitric oxide depresses GABAA receptor function via coactivation of cGMP-dependent kinase and phosphodiesterase. J Neurosci 1998;18(7):2342-9.
Yasukawa T, Kita T, Xue Y, Kita H. Rat intralaminar thalamic nuclei projections to the globus pallidus: a biotinylated dextran amine anterograde tracing study. J Comp Neurol 2004;471(2):153-67.

Yoshida T, Inoue R, Morii T, Takahashi N, Yamamoto S, Hara Y, et al. Nitric oxide activates TRP channels by cysteine S-nitrosylation. Nat Chem Biol 2006;2(11): 596-607.

Zhou FW, Matta SG, Zhou FM. Constitutively active TRPC3 channels regulate basal ganglia output neurons. J Neurosci 2008;28(2):473-82. 